\title{
Laidunnuskäytäntöjä ja -vaikutuksia merenrantaniityillä
}

\author{
Marika Niemelä \\ MTT Ruukki / Oulun yliopisto \\ Tutkimusasemantie 15,92400Ruukki,marika.niemela@mtt.fi
}

\section{Tiivistelmä}

Luonnonniittyjen laiduntamisen ja niiton vähennyttyä 1900-luvulla myös merenrantaniittyjen määrä on laskenut jyrkästi ja ne luokitellaan nykyisin äärimmäisen uhanalaiseksi luontotyypiksi. Huomattavaa osaa merenrantaniityistä hoidetaan perinnebiotooppien erityistuen avulla, pääasiassa nautakarjalla laiduntaen. Tarkkaa tietoa merenrantaniittyjen hoitotavoista, esimerkiksi käytetystä eläinaineksesta ei kuitenkaan ole ollut helposti saatavilla, ja nykymuotoisen rantalaidunnuksen ekologisista vaikutuksista tiedetään vielä suhteellisen vähän.

Tässä vuosina 2009-2011 toteutettavassa tutkimuksessa kootaan yksityiskohtaista tietoa merenrantaniittyjen hoitotavoista hyödyntäen Maaseutuviraston TIKE-tietokantaa ja viljelijäkyselyjä. Maastotutkimuksissa selvitetään rantalaitumilla yleisimmin käytettyjen nautaeläintyyppien (suurikokoiset lihakarjarodut, maitorotuiset hiehot) laidunnuksen vaikutuksia kasvillisuuteen. Tutkimusalueena on Pohjois-Pohjanmaan TE-keskuksen alue Perämeren rannikolla, jossa sijaitsee yli puolet Suomen merenrantaniittyjen kokonaispinta-alasta. Tutkimus on osa Suomen ympäristökeskuksen EU Life-hanketta (VACCIA) ja jatkumoa MTT:n LUMOLAIDUN-hankkeelle.

Liharotuisten oletetaan olevan maitorotuisia nautoja tehokkaampia laiduntajia rantaniityillä. Lihakarjalaitumilla kasvusto olisi tämän mukaan matalammaksi ja kattavammin syötyä ja kasvillisuuden peittävyys olisi alhaisempi kuin kevyempien maitorotuisten laiduntamilla niityillä, joilla kasvillisuuden oletetaan olevan sekä rakenteellisesti että lajistollisesti vaihtelevampaa.

Merenrantaniittyä sisältävien erityistukisopimuskohteiden kokonaispinta-ala oli PohjoisPohjanmaalla vuoden 2008 lopussa 2874 ha, josta noin 2460 ha (86 \%) on luokiteltu merenrantaniityksi. Noin $90 \%$ kohteiden kokonaisalasta hoidetaan laiduntaen, pääosin nautakarjan avulla. Nautakarjalaidunten kokonaisalasta $(2212$ ha $) \quad 80 \%$ on puhtaasti lihakarjalaitumia ja $14.5 \%$ maitorotuisilla laidunnettavia.

Kesällä 2009 tehtiin kasvillisuusselvitykset noin puolella (8) tutkittavien rantalaidunten määrästä ja vuonna 2010 tutkimukset jatkuvat uusilla kohteilla. Kesän 2009 tulosten perusteella kasvillisuus näyttäisi lihakarjalaitumilla olevan oletusten mukaisesti jonkin verran avoimempaa ja kattavammin syötyä kuin maitorotuisten nautojen laiduntamilla rantaniityillä. Tarkastelluissa muuttujissa esiintyi kuitenkin runsaasti vaihtelua myös vertailtavien ryhmien sisällä. Tutkimuksen lopulliset tulokset valmistuvat vuonna 2011.

Asiasanat: merenrantaniitty, perinnebiotooppi, erityistuki, laidunnus, lihakarja, maitorotuiset naudat, kasvillisuus 


\section{Johdanto}

Merenrantaniittyjen hoidossa on viimeisen vuosisadan kuluessa tapahtunut valtava muutos. Laajamittainen rantaniittyjen hyödyntäminen niittäen ja laiduntaen päättyi lähes kokonaan 1900luvun puoliväliin tultaessa, mitä seurasi muutamien vuosikymmenien umpeenkasvuvaihe. Avoimien merenrantaniittyjen kuten monien muidenkin perinnebiotooppien määrä laski murtoosaan aikaisempien vuosikymmenten tilanteeseen verrattuna; nykyisin merenrantaniityt luokitellaan äärimmäisen uhanalaiseksi luontotyypiksi (Schulman ym. 2008).

Vuosisadan lopulla merenrantaniittyjä ryhdyttiin hoitamaan uudestaan osana perinnebiotooppien tilan kohentamista. Maatalouden ympäristötuen erityistuki perinnebiotoopeille on mahdollistanut laajojen ranta-alueiden ottamisen hoidon piiriin. Hoitokäytännöt ovat kuitenkin muuttuneet huomattavasti aikaisempiin rantojen käyttötapoihin nähden. Niitto yhdistettynä sen jälkeiseen syyslaidunnukseen (aikaisemmin yleinen käytäntö) on nykyisin hyvin harvinainen hoitomuoto. Koko kesän jatkuva laidunnus on vallitseva hoitotapa ja entiseen verrattuna laidunnuspaine on todennäköisesti suurempi laidunnuksen tapahtuessa rajatummilla alueilla. Myös laiduneläimissä on tapahtunut suuri muutos karjan vaihtuessa enenevissä määrin maitorotuisista lihakarjaan. Tarkkaa tietoa merenrantaniittyjen hoitotavoista, esimerkiksi käytetystä eläinaineksesta ei kuitenkaan ole ollut helposti saatavilla, ja nykymuotoisen rantalaidunnuksen ekologisista vaikutuksista tiedetään vielä suhteellisen vähän.

Tässä vuosina 2009-2011 toteutettavassa tutkimuksessa kootaan yksityiskohtaista tietoa merenrantaniittyjen hoitotavoista hyödyntäen Maaseutuviraston TIKE-tietokantaa ja viljelijäkyselyjä. Maastotutkimuksissa selvitetään rantalaitumilla yleisimmin käytettyjen nautaeläintyyppien laidunnuksen vaikutuksia kasvillisuuteen huomioiden kohteiden eripituinen hoitohistoria. Lisäksi tutkimuksessa kartoitetaan ilmastonmuutoksen mahdollisia vaikutuksia rantalaiduntamiseen. Tutkimusalueena on Pohjois-Pohjanmaan TE-keskuksen alue Perämeren rannikolla, jossa sijaitsee yli puolet Suomen merenrantaniittyjen kokonaispinta-alasta (Suomen ympäristökeskus 2008).

Ympäristöviranomaisten ja viljelijöiden havainnot viittaisivat liharotuisten nautojen olevan maitorotuisiin verrattuna tehokkaampia laiduntajia merenrantaniityillä. Raskaampina rotuina myös lihakarjan tallausvaikutukset ovat todennäköisesti voimakkaammat kuin maitorotuisten nautojen. Tutkimuksen hypoteesina on, että rantaniittyjen kasvusto on lihakarjalaitumilla kokonaisuutena matalammaksi ja kattavammin syötyä ja kasvillisuuden peittävyys on alhaisempi kuin kevyempien maitorotuisten laiduntamilla niityillä. Lajistossa eläintyypin vaikutus näkyy ajan myötä matalakasvuisten lajien suurempana osuutena lihakarjalaitumilla. Maitorotuisten nautojen laiduntamilla niityillä kasvillisuuden voidaan olettaa olevan sekä rakenteellisesti että lajistollisesti vaihtelevampaa. Pitempään laidunnetuilla alueilla kasvillisuus on oletettavasti matalampaa ja kattavammin laidunnettua kuin laitumilla, jotka ovat hoitohistorialtaan nuorempia.

Tutkimus on osa Suomen ympäristökeskuksen EU Life-hanketta: Vulnerability assessment of ecosystem services for climate change impacts and adaptation (VACCIA) ja sen puitteissa Oulun yliopiston koordinoimaa Perämeren alueen tutkimuskokonaisuutta (ACTION 11: Assessment of impacts of climate change on biodiversity in coastal ecosystems and implementation of new policies and conservation strategies). Rantalaiduntutkimus on jatkumoa MTT:n LUMOLAIDUN-hankkeelle (Huuskonen 2006), jossa selvitettiin mm. merenrantaniittyjen rehusadon määrää ja laatua sekä karjan kasvua rantalaitumilla (Niemelä ym. 2008).

\section{Menetelmät}

Tutkimusta varten Maaseutuviraston TIKE-tietokannasta hankittiin tiedot Pohjois-Pohjanmaan TE-keskuksen alueella perinnebiotooppien erityistuen piirissä olevista sopimuskohteista, joihin sisältyy merenrantaniittyä (tilanne vuoden 2008 lopussa). Rantalaidunnusta harjoittaville 
viljelijöille lähetettiin kysely, jossa pyydettiin tietoja eläinaineksesta, laidunten hoitohistoriasta ym. laidunnuskäytännöistä. Maastotutkimusten käynnistämiseksi nautakarjaa laiduneläiminä käyttäville tiloille tehtiin soittokierros haastatellen tutkimusten kannalta tärkeimmät tekijät. Näiden tietojen perusteella tutkimukseen valittiin laidunnushistorialtaan eri-ikäisiä rantalaitumia, joilla vallitsevina laiduntajina ovat joko suurikokoiset lihakarjarodut tai maitorotuiset hiehot eli alueen rantalaitumilla yleisimmin käytetyt nautaeläintyypit.

Maastotutkimukset on jaettu kahdelle kesälle: vuonna 2009 kasvillisuusselvityksiä tehtiin kahdeksalla rantalaitumella ja vuonna 2010 tutkimuksia jatketaan noin samalla määrällä uusia kohteita. Kohteet sijoittuvat molempina kesinä Kalajoen ja Hailuodon välin kattavalle rannikkoalueelle. Kesällä 2009 tutkittujen lihakarjalaitumien pinta-ala oli keskimäärin 62 ha (keskihajonta \pm 37 ha, $n=5$ ) ja maitorotuisilla laidunnettavien 13 ha $( \pm 2.5$ ha; $n=3$ ). Eläinaines oli lihakarjalaitumilla isojen liharotujen (Simmental, Charolais, Limousin) emolehmiä vasikoineen ja maitorotuisten laiduntamilla 6 kk ikäisiä tai vanhempia Ayrshire- tai Friisiläishiehoja. Nykyinen laidunnus (kesä 2009 mukaan lukien) oli kestänyt kahdella lihakarjalaitumella 2-7 vuotta (luokka: Lih < 10v), kolmella lihakarjalaitumella 14-19 vuotta (luokka: Lih > 10v) ja kolmella hieholaitumella kymmenestä yli kolmeenkymmeneen vuotta (Luokka: Mai $>10 \mathrm{v}$ ). Eläintiheydet vaihtelivat edellä mainituissa hoitoluokissa seuraavasti kesällä 2009: 0,54-0,75 ey ha- $^{1}$ (Lih < 10v), 0,40-0,47 ey ha- ${ }^{1}$ (Lih $\left.>10 v\right)$ ja 0,32-0,72 ey ha- ${ }^{1}$ (Mai $\left.>10 v\right)$.

Kasvillisuustutkimukset tehdään keskellä laidunkautta; kesällä 2009 ne tehtiin 20.7-6.8 välisenä aikana. Eri puolille laidunta sijoitetaan neljä 50 x $50 \mathrm{~m}^{2}$ koealaa, joiden sisältä valitaan systemaattisella satunnaisotannalla viisi $1 \mathrm{~m}^{2}$ näytealaa koealan keskilinjaan sitoen mukaillen Perinnebiotooppien seurantaohjetta (Raatikainen 2009). Mahdollisia seurantatutkimuksia varten talletetaan keskilinjojen ja näytealojen koordinaatit, mutta linjoja tai aloja ei merkitä maastoon.

Koealan keskilinjan molemmista päistä otetaan valokuvat keskilinjan suuntaa sekä koealan kulmia kohti. Neliömetrin näytealoilta mitattavat muuttujat ovat kasvillisuuden keskikorkeus (5 nurmitikkumittausta/ näyteala), elävän ja kuolleen (karike) kasvuston peittävyys, syödyn kasvuston ja paljaan maan osuus, valtalajien peittävyydet sekä lista muista näytealalla esiintyvistä lajeista. Kasvillisuuden korkeutta mitataan myös laitumen muissa osissa tehden yhteensä 100 nurmitikkumittausta (Virkajärvi 1999) linjoilta viiden metrin välein (askelparitarkkuudella). Samalla mitattavasta kasvista määritetään laji ja onko kasvia syöty. Näin kasvillisuuden vaihtelusta saadaan laajempi kuva laitumella ja voidaan vertailla eri otantamenetelmiä keskenään. Aineiston keruu on puolivälissä eikä tilastollisia testauksia ole tässä vaiheessa vielä tehty. Kesän 2009 tuloksia tarkastellaan alla lähinnä keski- ja hajontalukujen perusteella.

\section{Alustavia tuloksia}

Merenrantaniittyjä oli Pohjois-Pohjanmaan TE-keskuksen alueella perinnebiotooppien erityistuen piirissä vuoden 2008 lopussa 51 viljelijällä. Sopimuksiin sisältyi yhteensä 89 erillistä hoitokohdetta, joiden kokonaispinta-ala oli 2874 ha. Tästä noin 2460 ha (86 \%) on luokiteltu merenrantaniityksi; muut kohteisiin sisältyvät osat olivat yleensä erilaisia puustoisia luontotyyppejä. Hoidettavien kohteiden kokonaispinta-ala on kolminkertaistunut verrattuna vuoden 2002 tilanteeseen (Kuva 1).

Vallitseva hoitotapa on laidunnus, niitto on ainoana hoitomuotona vain $11 \%$ :lla kohteiden kokonaispinta-alasta (Taulukko 1). Laiduneläiminä käytetään eniten nautoja, erityisesti lihakarjaa. Nautakarjalaidunten kokonaisalasta (2212 ha) $80 \%$ on puhtaasti lihakarjalaitumia ja $14,5 \%$ maitorotuisilla laidunnettavia (kaksi sekalaidunta on luokiteltu taulukossa 1 kohtaan "Muut"). Myös lampailla hoidettavia kohteita on kohtalaisen paljon, mutta pinta-alallisesti ne ovat melko pieniä alueita ja sisältävät merenrantaniittyä suhteellisen vähän (usein puustoisia saarilaitumia). 


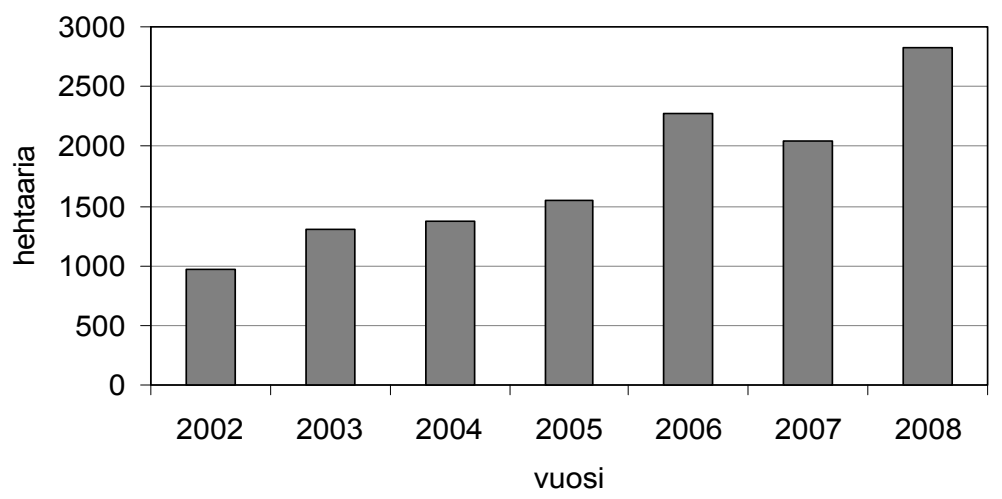

Kuva 1. Perinnebiotooppien erityistuen piirissä olevien kohteiden (merenrantaniittyä sisältävät) kokonaispinta-ala Pohjois-Pohjanmaan TE-keskuksen alueella.
Taulukko 1. Merenrantaniittyä sisältävien erityistukialueiden jakautuminen eri tavoin hoidettaviin kohteisiin vuonna 2008 Pohjois-Pohjanmaalla.

\begin{tabular}{lrrr}
\hline Hoitotapa & $\mathbf{l k m}$ & $\mathbf{h a}$ & $\mathbf{\%}$ \\
\hline Niitto & 22 & 321 & 11 \\
Laidunnus & 67 & 2553 & 89 \\
\multicolumn{1}{c}{ Yhteens $\ddot{a}$} & 89 & 2874 & \\
\hline Laiduntajat & $\mathbf{l k m}$ & $\mathbf{h a}$ & $\mathbf{\%}$ \\
\hline Lihakarja & 24 & 1770 & 69.3 \\
Maitorotuiset & 9 & 320 & 12.5 \\
Lampaat & 28 & 305 & 12.0 \\
Muut & 6 & 158 & 6.2 \\
\multicolumn{1}{c}{ Yhteens $\ddot{a}$} & 67 & 2553 & \\
\hline
\end{tabular}

Tutkituilla rantalaitumilla kasvillisuuden keskikorkeus vaihteli pääsääntöisesti $20-30 \mathrm{~cm}$ välillä (Kuva 2). Yli 10 vuotta laidunnettujen lihakarjalaidunten ryhmästä löytyvät koko aineiston ääripäitä edustavat laitumet, joilla näytealojen keskikorkeudet olivat noin $9 \mathrm{~cm}$ ja $80 \mathrm{~cm}$. Viimeksi mainitun korkeakasvuisen (valtalajina järviruoko) laitumen matalakasvuisemmat osat tulivat paremmin edustetuiksi linjamittauksissa (ka. $35 \mathrm{~cm})$, mistä johtuu linjamittauksissa saatu alhaisempi keskikorkeus kyseisessä ryhmässä (Kuva 2). Muiden kasvillisuuden rakennepiirteiden perusteella kasvusto näyttäisi olevan peitteisempää maitorotuisten nautojen laiduntamilla rantaniityillä kuin lihakarjalaitumilla, mutta erot ovat osin pieniä ja hajontaa on runsaasti (Taulukko 2).

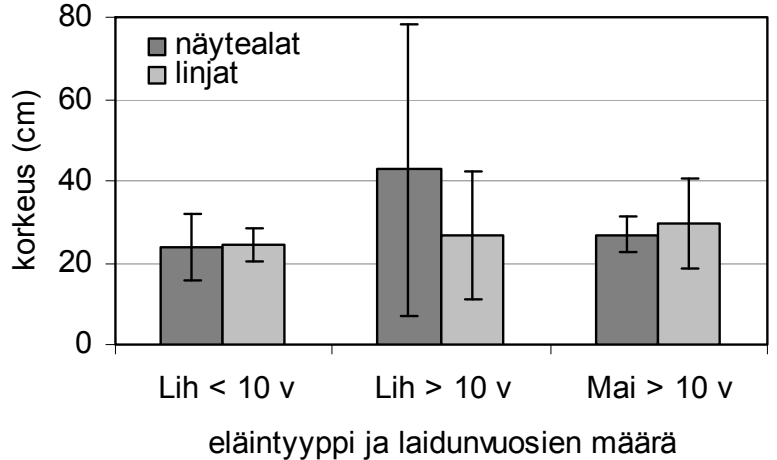

Kuva 2. Kasvuston korkeus (keskiarvot \pm keskihajonnat) näyteala- ja linjamittausten perusteella Pohjois-Pohjanmaan rantalaitumilla 2009. Selitteet ja laidunten määrät taulukossa 2.
Taulukko 2. Kasvuston rakenteen vaihtelu (keskiarvot \pm keskihajonnat) eri tavoin hoidetuilla rantalaitumilla Pohjois-Pohjanmaalla 2009. Lih = lihakarjalaitumet, Mai $=$ maitorotuisilla laidunnetut; laidunnettu alle $(<10 \mathrm{v})$ tai vähintään (> 10v) 10 vuotta; $\mathrm{n}=$ tutkittujen laidunten määrä eri hoitoluokissa.

\begin{tabular}{lccc}
\hline & $\begin{array}{c}\text { Lih }<10 \mathrm{v} \\
(\mathrm{n}=2)\end{array}$ & $\begin{array}{c}\text { Lih }>10 \mathrm{v} \\
(\mathrm{n}=3)\end{array}$ & $\begin{array}{c}\text { Mai }>10 \mathrm{v} \\
(\mathrm{n}=3)\end{array}$ \\
\hline Peittävyys (\%) & $53 \pm 4,8$ & $66 \pm 5,5$ & $68 \pm 1,3$ \\
Karike (\%) & $50 \pm 1,4$ & $59 \pm 43$ & $81 \pm 11$ \\
Paljasta maata (\%) & $24 \pm 11$ & $17 \pm 17$ & $7,2 \pm 6,5$ \\
Syöty (\%) & $59 \pm 4,1$ & $51 \pm 29$ & $29 \pm 20$ \\
\hline
\end{tabular}

Matalakasvuiset kasvilajit olivat valtalajeina $60 \%$ :lla (keskihajonta $\pm 49 \%$ ) tutkituista näytealoista yli 10 vuotta laidunnetuilla lihakarjalaitumilla. Alle 10 vuotta laidunnetuilla lihakarjalaitumilla ja yli 10 vuotta maitorotuisilla naudoilla laidunnetuilla laitumilla matalakasvuiset lajit vallitsivat alle puolella tutkituista näytealoista (43 $\pm 25 \%$ ja $43 \pm 20 \%)$. Ryhmien sisäinen hajonta on kuitenkin niin suurta, etteivät erot todennäköisesti ole merkitseviä. Keskimääräinen lajirunsaus oli suurin alle 10 vuotta laidunnetuilla lihakarjalaitumilla $(8,1 \pm 2,2$ lajia $\mathrm{m}^{-2}$ vrt. $5,8 \pm 0,3$ ja $7,7 \pm 2,5$ lajia $\mathrm{m}^{-2}$ yli 10 vuotta laidunnetuilla lihakarja- ja hieholaitumilla). 


\section{Johtopäätökset}

Merenrantaniittyjä on arvioitu olevan jäljellä 2500 ha Suomen puoleisella Perämeren rannikolla (Suomen ympäristökeskus 2008). Perinnebiotooppien erityistukisopimuksiin sisältyi PohjoisPohjanmaalla vuoden 2008 lopussa noin 2460 ha merenrantaniittyä. Vaikka em. selvitysten luvut eivät ole täysin vertailukelpoisia (erityistukisopimuksissa merenrantaniittyjen erottaminen muista luontotyypeistä epätarkempaa), kertovat ne kuitenkin huomattavan osan Perämeren rantaniityistä olevan hoidon piirissä. Noin $90 \%$ merenrantaniittyä sisältävien erityistukialueiden kokonaisalasta Pohjois-Pohjanmaalla hoidetaan nykyisin laiduntaen, pääosin nautakarjan avulla. Nautakarjalaidunten kokonaisalasta $80 \%$ hoidetaan liharotuisilla ja 14,5\% maitorotuisilla naudoilla.

Maastotutkimukset ovat vasta puolivälissä (puolet aineistosta kerätty 2009), joten tähän mennessä saaduista tuloksista ei kovin pitkälle meneviä johtopäätelmiä voi vielä tehdä. Kasvillisuus näyttäisi lihakarjalaitumilla olevan oletusten mukaisesti jonkin verran avoimempaa ja kattavammin syötyä kuin maitorotuisten nautojen laiduntamilla rantaniityillä. Tarkastelluissa muuttujissa esiintyi kuitenkin runsaasti vaihtelua myös vertailtavien ryhmien sisällä. Tutkimuksen lopulliset tulokset valmistuvat vuonna 2011.

\section{Kirjallisuus}

Huuskonen, A. (toim.) 2006. LUMOLAIDUN Maisemalaiduntaminen luonnon monimuotoisuuden lisääjänä tasapaino monimuotoisuuden ja tuottavuuden välillä. Maa- ja elintarviketalous 79. Maa- ja elintarviketalouden tutkimuskeskus, Jokioinen. $418 \mathrm{~s}$.

Niemelä., M., Huuskonen, A., Jaakola, S., Joki-Tokola, E. \& Hyvärinen, M. 2008. Coastal meadows as pastures for beef cattle. Agrig Ecosyst Environ 124: 179-186.

Raatikainen, K. (toim.) 2009. Perinnebiotooppien seurantaohje. Metsähallituksen luonnonsuojelujulkaisuja. Sarja B 117. 109 s.

Schulman. A., Alanen, A., Haggström, C-A., Huhta, A-P., Jantunen, J., Kekäläinen, H., Lehtomaa, L., Pykälä, J. \& Vainio, M. 2008. Perinnebiotoopit. In Raunio A, Schulman A \& Kontula T (toim.) Suomen luontotyyppien uhanalaisuus - Osa 2: Luontotyyppien kuvaukset. Suomen ympäristökeskus, Helsinki. Suomen ympäristö 8/2008: 397-465.

$\begin{array}{lcccc}\text { Suomen } & \text { ympäristökeskus } 2008 . & \text { Taulukko } & \text { merenrantaniittyjen } & \text { yhteispinta-aloista } \\ \text { tausta-aineisto } & \text { Perinnebiotooppien } & \text { asiantuntijaryhmän } & \text { Luontotyyppien }\end{array}$ uhanalaisuuden arviointi. Julkaisematon aineisto.

Virkajärvi, P. 1999. Comparison of three indirect methods for prediction of herbage mass of timothy meadow fescue pastures. Acta Agric. Scand. B 49: 75-81. 